Int. J. Electrochem. Sci., 15 (2020) 4481 - 4493

International Journal of

ELECTROCHEMICAL

SCIENCE

$\underline{\text { WWW.electrochemsci.org }}$

\title{
Performance Assessment of a Combined System Using a Biological Aerated Filter and Electro-coagulation for Advanced Wastewater Treatment
}

\author{
Hyung-Soo Shin ${ }^{1}$, Woo-Yeol Kim ${ }^{2}$, Dong-Jin Son ${ }^{1}$, and Ki-Ho Hong ${ }^{3, *}$ \\ ${ }^{1}$ Department of Advanced Technology Fusion, Konkuk University, Seoul, Republic of Korea \\ ${ }^{2}$ Materials \& Membranes Co., Ltd., Gangnung-si, Gangwon-do, Republic of Korea \\ ${ }^{3}$ Department of Technology Fusion Engineering, Konkuk University, Seoul, Republic of Korea \\ *E-mail: khhong@konkuk.ac.kr
}

doi: $10.20964 / 2020.05 .68$

Received: 2 January 2020 / Accepted: 3 March 2020 / Published: 10 April 2020

In this study, a biological aerated filter (BAF), used for the preferred elimination of organic matter and ammonia nitrogen, was combined with an electro-coagulation process for guaranteed selective phosphorus removal. A synthetic feed was prepared and used to represent the concentrations of typical organics, nitrogen, and phosphorus in municipal wastewater in Korea. The performance of the combined system in the removal of organic matter, nitrogen, and phosphorus was assessed, and the internal behavior of major contaminants was also evaluated. Higher removal of organics with a concentration lower than $4 \mathrm{mg} / \mathrm{L}$ could be achieved under a retention time of $1 \mathrm{~h}$ or longer; however, the concentration of organic matter in the effluent increased significantly at shorter retention times, i.e., less than $1 \mathrm{~h}$. When the retention time was further reduced from 1 to $0.5 \mathrm{~h}$, a reduction in the nitrification efficiency was also observed because of an insufficient reaction time for the oxidation of ammonia nitrogen by microorganisms. As the electrolysis progressed, an additional removal of organics could be performed by up to $2 \mathrm{mg} / \mathrm{L}$ within $5 \mathrm{~min}$. The phosphorus removal was performed by the BAF; however, the electrolysis process used copper electrodes. A phosphorus concentration of $0.1 \mathrm{mg} / \mathrm{L}$ or less could be guaranteed successfully using this combined method. Thus, the combination of the BAF and electrocoagulation procedure is an easy and reliable alternative for advanced wastewater treatment.

Keywords: Advanced wastewater treatment, Biological aerated filter, Electro-coagulation, Electrolysis

\section{$\underline{\text { FULL TEXT }}$}

(C) 2020 The Authors. Published by ESG (www.electrochemsci.org). This article is an open access article distributed under the terms and conditions of the Creative Commons Attribution license (http://creativecommons.org/licenses/by/4.0/). 